\title{
Erratum to: Forensics in Telecommunications, Information and Multimedia
}

\author{
Matthew Sorell \\ School of Electrical and Electronic Engineering, University of Adelaide, \\ SA 5005, Australia \\ matthew.sorell@adelaide.edu.au
}

\section{Erratum to: \\ M. Sorell (Ed.)}

Forensics in Telecommunications, Information and Multimedia

DOI: $10.1007 / 978-3-642-02312-5$

The book was inadvertently published with an incorrect name of the copyright holder. The name of the copyright holder for this book is: (C) ICST Institute for Computer Science, Social Informatics and Telecommunications Engineering. The book has been updated with the changes.

The updated original online version for this book can be found at DOI: $10.1007 / 978-3-642-02312-5$ 